\title{
Hidden risk of nosocomial transmission: a presymptomatic novel coronavirus disease-19 (COVID-19) case with ischemic stroke
}

\author{
Wensen Chen ${ }^{1 *}$, Junhong Wang ${ }^{2 *}$, Wei Cheng ${ }^{3}$, Dapeng Li $^{4}$, Yishan Zheng ${ }^{5}$, Jinsong Zhang ${ }^{6}$, Yun Liu ${ }^{7}$ \\ ${ }^{1}$ Department of Infection Management, ${ }^{2}$ Department of Cardiology, The First Affiliated Hospital with Nanjing Medical University, Nanjing, China; \\ ${ }^{3}$ Department of Genetics, Albert Einstein College of Medicine, Bronx, New York, USA; ${ }^{4}$ Department of Radiology, The First Affiliated Hospital with \\ Nanjing Medical University, Nanjing, China; ${ }^{5}$ Department of Critical Medicine, The Second Hospital of Nanjing, Nanjing, China; ${ }^{6}$ Department of \\ Emergency Medicine, ${ }^{7}$ Department of Geriatrics Endocrinology, The First Affiliated Hospital with Nanjing Medical University, Nanjing, China \\ \#These authors contributed equally to this work. \\ Correspondence to: Prof. Yun Liu. Department of geriatrics endocrinology, the First Affiliated Hospital with Nanjing Medical University, Nanjing, \\ China. Email: liuyun@njmu.edu.cn. \\ Provenance and Peer Review: This article was a free submission to the editorial office, fournal of Thoracic Disease. The article did not undergo external \\ peer review.
}

Submitted Mar 10, 2020. Accepted for publication Apr 03, 2020.

doi: 10.21037/jtd-20-1249

View this article at: http://dx.doi.org/10.21037/jtd-20-1249

The first case of COVID-19 emerged in early Dec, 2019 in Wuhan, China and outbreak since Jan, 2020 (1). As of Feb 15,2020 , a total of 66,576 cases were reported in China. $29 \%$ COVID-19 transmission was presumably healthcareassociated (2), indicating SARS-CoV-2 nosocomial infection is an important transmission route. SARS-CoV-2 was supposed to be contagious during incubation phase $(3,4)$. Therefore, admitting screening presymptomatic carriers, who are usually ruled out by current symptom or epidemiological history-based criteria (5), become crucial for SARS-CoV-2 nosocomial infection control. Herein, we report a case of successful diagnosis, prompt quarantine and efficient treatment of an presymptomatic COVID-19 patient admitted with acute ischemic stroke.

On Feb 6, 2020, a 72-year-old woman was admitted to our emergency department. She had a sudden dropped muscle force of left upper limb and slur in her speech for 8 hours. She has hypertension for 10 years. On admission, her temperature was $37.2^{\circ} \mathrm{C}\left(99^{\circ} \mathrm{F}\right)$, and she didn't complain any signs or symptoms relevant to COVID-19. Her ECG indicated atrial fibrillation, and her head CT showed no hemorrhage or obvious infraction sites. Her neutrophil ratio was $65 \%(40.0-75.0 \%)$, lymphocyte was $17 \%$ (20.0-50.0\%) and procalcitonin (PCT) was $<0.1 \mathrm{ng} / \mathrm{mL}$, indicating low possibility of bacterial infection. However, the proBNP was $1,090 \mathrm{pg} / \mathrm{Ml}(0-125 \mathrm{pg} / \mathrm{mL})$, indicating a high likelihood of heart failure, and then a chest CT was performed. Unexpectedly, the chest CT indicated multiple patchy and ground-glass opacities, suggesting a possibility of pneumonia (Figure 1). Her throat swabs were then obtained and tested positive for SARS-CoV-2 with realtime RT-PCR (ct value: 21). The patient was immediately proceeded to quarantine at a COVID-19-designated hospital. After 7-day of antiviral treatment (darunavir plus inhaled interferon- $\alpha$ ), her virus test turned to negative and she is now stable.

Admission of contagious presymptomatic carriers put healthcare professionals and patients at high risk of transmission (2). Our procedure successfully diagnosed an presymptomatic COVID-19 carrier by chest CT examination. Given the high virus load, our diagnosis successfully prevented a potential SARS-CoV-2 nosocomial transmission in our hospital. Therefore, it is highly urgent to establish a new special procedure to add lung CT and/or serological tests for admitted patients at least in COVID-19 affected regions.

Patients with chronic comorbidities are usually susceptible to infection (2). Moreover, COVID-19 patients with comorbidities showed more severe symptoms and higher risk to receive ICU care (2). Earlier diagnosis and prompt treatment are therefore crucial for the survival of this population. Our case presented a successful treatment of a patient before symptoms appear. It is also necessary to emphasize the importance of respiratory protection to 

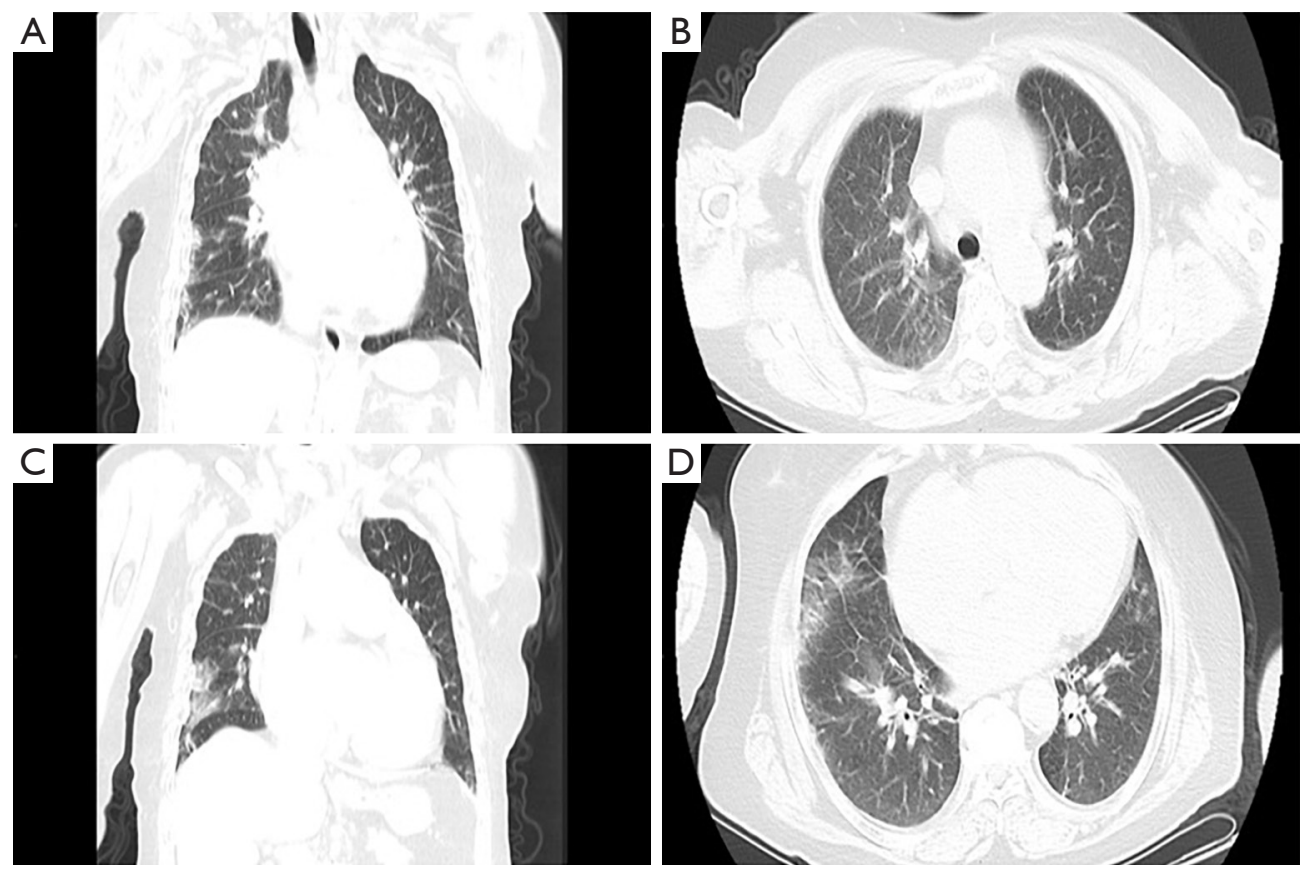

Figure 1 Chest imaging of the patient. Chest CT scans of the lung showed bilateral, multiple patchy, ground-glass opacities, accompanied by interlobular septal thickening. CT, computed tomography.

minimize the virus transmission in susceptible populations.

\section{Acknowledgments}

Funding: The present study was supported by grants from the National key Research \& Development plan of Ministry of Science and Technology of the People's Republic of China (Grant no. 2018YFC1314900, 2018YFC1314901, Liu Y), the Natural Science Foundation of China (No. 81570328, Wang JH) and Jiangsu Key Provincial Talents Program (No. ZDRCB2016005, Wang JH).

\section{Footnote}

Conflicts of Interest: All authors have completed the ICMJE uniform disclosure form (available at http://dx.doi. org/10.21037/jtd-20-1249). The authors have no conflicts of interest to declare.

Ethical Statement: The authors are accountable for all aspects of the work in ensuring that questions related to the accuracy or integrity of any part of the work are appropriately investigated and resolved. The images are published under agreement of the patient.
Open Access Statement: This is an Open Access article distributed in accordance with the Creative Commons Attribution-NonCommercial-NoDerivs 4.0 International License (CC BY-NC-ND 4.0), which permits the noncommercial replication and distribution of the article with the strict proviso that no changes or edits are made and the original work is properly cited (including links to both the formal publication through the relevant DOI and the license). See: https://creativecommons.org/licenses/by-nc-nd/4.0/.

\section{References}

1. Zhu N, Zhang D, Wang W, et al. A Novel Coronavirus from Patients with Pneumonia in China, 2019. N Engl J Med 2020;382:727-33.

2. Wang D, Hu B, Hu C, et al. Clinical Characteristics of 138 Hospitalized Patients With 2019 Novel CoronavirusInfected Pneumonia in Wuhan, China. JAMA 2020. [Epub ahead of print].

3. Thompson R. Pandemic potential of 2019-nCoV. Lancet Infect Dis 2020;20:280.

4. Sanche S, Lin YT, Xu C, et al. The Novel Coronavirus, $2019-\mathrm{nCoV}$, is highly contagious and more infectious than initially estimated. medRxiv 2020.02.07.20021154; 
Available online: https://doi.org/10.1101/2020.02.07.20 021154.

5. Jin YH, Cai L, Cheng ZS, et al. A rapid advice guideline for the diagnosis and treatment of 2019 novel coronavirus (2019-nCoV) infected pneumonia (standard version). Mil Med Res 2020;7:4.

Cite this article as: Chen W, Wang J, Cheng W, Li D, Zheng Y, Zhang J, Liu Y. Hidden risk of nosocomial transmission: a presymptomatic novel coronavirus disease-19 (COVID-19) case with ischemic stroke. J Thorac Dis 2020;12(6):3442-3444. doi: 10.21037/jtd-20-1249 